\title{
LA ACCION DE RESPONSABILIDAD CIVIL Y SU FUNCION TUTELAR DEL DERECHO AL HONOR
}

Juan José MARI CASTELLO-TARREGA

Magistrado 

El tema sometido a nuestra consideración lleva como título genérico el de "la responsabilidad civil por lesiones del derecho al honor", expresión que obviamente hace referencia a la obligación de reparar las consecuencias derivadas de ese particular hecho ilícito. Su especialidad vendrá determinada únicamente en la medida en que las reglas generales sobre atribución de responsabilidad civil, se vean afectadas por la naturaleza inmaterial del derecho violado. Aún así, el tema es lo suficientemente amplio como para que pueda ser tratado aquí por extenso. Conviene, por lo tanto, centrar la exposición en algún aspecto particular de la cuestión.

A primera vista pudiera pensarse que reconducir el tema a la perspectiva desde la que va a ser contemplado por el Juez civil, es salirse del contexto general de este curso, en el que se conecta la libertad de expresión con el derecho penal.

Pienso, no obstante, que conviene hacerlo. No sólo porque la responsabilidad civil es materia sobre la que se opera con técnicas de derecho privado, sino que-como veremos-por medio de la acción de responsabilidad civil se puede alcanzar un alto grado de eficacia en la protección del derecho a la honra.

Me ha interesado primero resaltar como nuestra jurisprudencia civil ha conseguido configurar esta acción, para mejor reflexionar después en torno a aquellas cuestiones que el nuevo orden constitucional va a hacer aflorar en el futuro, y que tendrá que plantearse-y resolver-tambièn el Juez civil cuando ante él se ejercite una acción de esta naturaleza.

Unas veces con fundamento en razones éticas, otras con apoyo en razones técnico-jurídicas, se cuestionó antaño la resarcibilidad de los perjuicios derivados por atentados contra el honor. Hoy en día es pacífica la opinión que da respuesta afirmativa a ese interrogante. El principio de que se parte puede formularse así: todo atentado contra la honra de una persona comporta un correlativo deber para su autor de reparar el daño, al margen de la responsabilidad penal que pueda engendrar.

En nuestro Derecho, el Código Penal vigente, siguiendo al de 1928, contiene una norma de derecho positivo (artículo 104), que permite el resarcimiento de los daños materiales y morales derivados de atentados al 
honor por hechos tipificados en el mismo Código como delictivos. Pero la jurisprudencia de la Sala 2. ${ }^{a}$ del Tribunal Supremo, pese a que los Códigos Penales de 1870 y 1932 no recogían esta norma, había ya de antes superado (Sentencia de 14-11-34) su vieja doctrina que negaba la posibilidad de exigencia de responsabilidad civil por el delito de injurias (Sentencia 6-121892)(1).

El Código Civil, a diferencia de lo que acontece en el Código Penal, no contiene norma o precepto específico alguno que tutele en vía civil el derecho al honor. Sin embargo, la doctrina y la jurisprudencia han llegado a ser unánimes y coincidentes en configurar el «honor" como un "bien», un "interés» o un "derecho» jurídicamente tutelado también por el derecho privado.

Cuál haya sido ese proceso a través del cual se ha llegado a esa conclusión, pese a la ausencia de normas expresas, interesa siquiera brevemente ponerlo de relieve, en cuanto que es buen ejemplo de adecuación del ordenamiento jurídico a las exigencias de la dignidad de la persona humana y de las realidades sociales de nuestro tiempo.

A ello ha contribuido, en primer lugar, la construcción jurídica de los derechos de la personalidad, cuya existencia tampoco se cuestiona ya, aunque es verdad que esté todavía sin precisar su naturaleza jurídica, y sin completar su régimen jurídico, en gran medida interdisciplinar. Los derechos de la personalidad no son más que el trasunto fiel de los derechos humanos al campo de las relaciones entre particulares. De aquí que en su regulación interfieran normas de naturaleza pública.

A falta de una norma que, a la manera del artículo 70 del Codigo Civil portugués(2), recoja el principio general de respeto a la persona húmana, protegiéndola de cualquier ofensa o amenaza a su personalidad, física o moral, no obstante, la realidad y vigencia de este principio ha sido inducido de particulares normas jurídicas, que se ha incorporado así a nuestro ordenamiento jurídico como norma de derecho positivo, a tenor del artículo 1.4 del Código Civi|(3). En su virtud, toda violación del mismo genera responsabilidad para su autor, y una correlativa facultad para el ofendido de impedir que continúe la afrenta y de exigir la reparación del daño que se le hubiere irrogad $(\alpha)$. 
En segundo lugar hay que señalar la construcción jurídica del «daño moral", que-no sin esfuerzos-ha concluido en un sólido cuerpo de doctrina que permite atender las exigencias de reparación de los daños sin contenido económico. Se trata de indemnizar "los sufrimientos morales", los "dolores físicos", "las perturbaciones de ánimo", "la alteración de espíritu», "el sentimiento de amargura o dolor" que el sujeto sufre por el menoscabo o demérito de que ha sido objeto en su dignidad. Precisamente aquí se encuentra el origen de las dificultades técnico-jurídicas que se oponían a la resarcibilidad de los atentados contra la honra: no siendo valorable el honor, no es posible fijar la cantidad en que consista el perjuicio(5).

Junto a lo anterior, la doctrina y la jurisprudencia no ha dudado en hacer una interpretación del artículo 1902 del Código Civil, al servicio de ese principio general de respeto a la persona humana a que se ha hecho alusión. En su interpretación originaria, este precepto quedaba reducido a fundar la responsabilidad por culpa de los daños materiales causados a un tercero(6). Luego, su genérica formulación, como al igual ha ocurrido con aquel precepto del Codigo francés en el que se inspiro, ha hecho posible una interpretación flexible del mismo, que ha permitido comprender en su ámbito tanto los "daños materiales" como los "morales", ha hecho factible su adaptación a las necesidades surgidas por el empleo de la actual tecnología (principio de expansión en la apreciación de la prueba de la culpabilidad-principio de agotamiento de la diligencia debida), y lo ha elevado a la función de ser fundamento jurídico positivo de protección de la persona humana, contemplada ya no sólo en su vertiente patrimonial, sino en su integridad, en consonancia con lo que se ha llamado «recuperación de la persona para el derecho privadow(7).

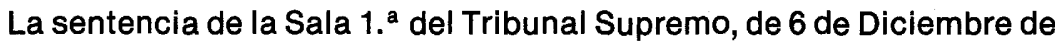
1912 , inicia toda esta nueva corriente jurisprudencial. Pronunciada en un supuesto de ataque a la honra de una mujer por medio de la prensa, esta sentencia ha dado lugar a numerosos comentarios(8). Aquí nos interesa recogerla en cuanto que inicia toda una corriente jurisprudencial favorable al concepto del "daño moral" y a la configuración del "honor" como un bien jurídico protegible, susceptible no sólo de generar una responsabili- 
dad penal, sino también de índole civil, traducida en una obligación indemnizatoria de los perjuicios ocasionados, apartándose en este sentido por completo de una anterior orientación mantenida por la Sala 2. ${ }^{a}$ del Tribunal Supremo, con relación al delito de injurias.

La lectura de esta sentencia debe hacerse en el contexto social de la época en que fue dictada. Probablemente no siguiéramos hoy en día la doctrina o justificación que la inspira, para proteger la honra de la mujer soltera. Apoyándose en la idea de que con ello se reducen sus perspectivas para contraer matrimonio, antes cabe hablar de "lucro cesante" que de su propia dignidad personal. Esta concepción es to que hace confuso el concepto que la Sentencia mantiene del "daño moral», al no aparecer claramente diferenciado del "daño patrimonial indirecto".

Si lo anterior es cierto, también lo es que la doctrina de la época tampoco había llegado a orientaciones claras y generalmente admitidas. Seguía siendo controvertida la cuestión de si el artículo 1902 del Código Civil comprendía también los "daños morales", o sólo los "materiales». En los años 1917 y 1918, posteriores pues a la sentencia, todavía se publicaron sendos trabajos en la "Revista de Derecho Privado", en los que se seguía manteniendo, siquiera fuera para lamentarlo, la tesis negativa(9). La sentencia comentada no se atreve a responder a esta cuestión, que directamente se le plantea al Tribunal en la formulación de los motivos del recurso. Se impugnan las sentencias de la instancia, entre otros motivos, por violación del artículo 1902 del Código Civil, al afirmarse en ellas que en dicho precepto se comprenden también los «daños morales». El Tribunal se limita a constatar la existencia de un principio jurídico que protege la honra y la fama de la mujer, y cita "Las Partidas" no como derecho vigente, sino como constatación de la "preexistencia" de ese principio en nuestro derecho histórico; pero no se hace referencia alguna a si el fundamento jurídico de esa protección puede encontrarse o no en el artículo 1902 del Código Civil.

Con posterioridad a esa fecha, el Tribunal Supremo tuvo ocasión de pronunciarse en vía civil en algún otro supuesto de atentados al honor(10). A mi juicio, no es hasta la Sentencia de 31 de marzo de 1930 en que claramente funda la exigencia de responsabilidad civil en el artículo $1902 \mathrm{del}$ Código Civil. 
En realidad el Tribunal Supremo ha tenido muy escasas ocasiones de pronunciarse sobre la materia. Se puede afirmar que no superan la docena(11). $Y$ en algunas de ellas, nos encontramos antes bien en supuestos de competencia desleal-o lo que hoy podría configurarse como publicịdad ilícita-(12), pero que su insuficiente regulación llevó a instar su protección por la vía del llamado "honor mercantil o comercial", como manifestación particular del sentimiento personal del honor.

Es la Sentencia de 7 de Febrero de 1962, que contiene hasta el presente el más acabado resumen de todo el cuerpo de doctrina sobre la protección al honor por vía civil(13). Esta doctrina se puede sintetizar así:

1. ${ }^{\circ}$ Se afirma el honor como derecho de la personalidad, cuya tutela tiene por objeto asegurar la integridad moral de la persona.

2. . Esta tutela puede hacerse valer también por vía civil.

3. ${ }^{-}$El honor, en vía civil, se define en un sentido muy amplio, abrazando todas las manifestaciones del sentimiento de estimación de la persona (honor civil, comercial, científico, literario, artístico, profesional, etc.).

4. ${ }^{\circ}$ Su protección se confiere en razón a la ilicitud del comportamiento del ofensor, independientemente de todo daño patrimonial directo 0 indirecto.

5. Se otorga al ofendido un poder de accionar contra el ofensor, bien para obtener sólo el reconocimiento de la ilicitud de su comportamiento, bien para el resarcimiento de los daños, bien para hacer cesar el acto injurioso y de hacer suprimir el medio con el que el mismo haya sido realizado y pueda ser divulgado.

6..$^{\circ}$ Se proclama que en el Derecho patrio están incluidas en la acción de resarcimiento del art. 1902 del Código Civil las lesiones contra el honor.

7..$^{\circ}$ Se declaran resarcibles los daños patrimoniales directos o indirectos, que sean consecuencia de la ofensa inferida, y también los «daños morales"; que se configuran con precisión.

8. ${ }^{\circ}$ Se atribuye al denominado "dinero de dolor" una función "compensatoria", pero también "satisfactoria" y "punitiva". 
9. ${ }^{\circ}$ Se proclama la posibilidad de coexistencia de una doble indemnización por daños materiales y por daños morales, sin que por ello se indemnice doblemente por un mismo hecho, por tener cada uno de ellos sustantividad independiente.

10..$^{-L a}$ valoración de los daños corresponde hacerla al Juzgador conforme a las exigencias de la equidad, y de modo discrecional, sin sujeción a pruebas de tipo objetivo y en atención sólo a las circunstancias y necesidades del caso concreto.

En la doctrina jurídico penal, el tema del honor ha sido ampliamente tratado. Los civilistas incluyen el "honor" dentro del capítulo de los derechos de la personalidad, pero de ordinario se refieren a su régimen jurídico en vía civil en términos de gran generalidad, sin mayores precisiones que las contenidas en la Sentencia comentada. Doctrinalmente, sin duda alguna, el aspecto más acabado es el del «daño moral». La necesidad de tutelar el honor en vía civil, y, particularmente, de otorgarle una acción indemnizadora, ha contribuido en singular medida a elaborar este concepto; pero el concepto y su regulación, no son doctrina específica del honor o la honra, sino que tiene su engarce en una teoría general sobre la responsabilidad civil o sobre el daño.

De otro lado, toda esta construcción sobre la responsabilidad civil por atentados al honor, se ha elaborado sobre el esquema de la responsabilidad extracontractual o aquiliana, en la que sigue siendo la culpa su fundamento, y esencial la existencia de un resultado lesivo separado del acto o acción que lo ocasiona. Sin embargo, cuando de la lesión de bienes inmateriales se trata-caso de la honra-, aún cuando conceptualmente quepa diferenciar acción y daño, es más dificultoso desconectarlos entre sí. EI concepto de la antijuridicidad, o ilicitud del acto, sin dejar de predicarse en la culpa extracontractual, cobra aquí un particular relieve.

Es verdad que una progresiva orientación doctrinal y jurisprudencial ha facilitado los remedios precisos para ciertos casos. Así, el principio de expansión en la apreciación de la prueba, que obvia las dificultades de probanza de la culpa. La jurisprudencia ha llegado incluso a relevar de la prueba del daño, cuando de los hechos mismos en que consista la infrac- 
ción, se sigue o se deduce necesariamente su existencia. (Sentencia 28 de abril de 1969).

De todas formas, cabe preguntarse sobre la insuficiencia de esta construcción para encontrar respuestas válidas ante nuevas realidades. Que no son otras, a mi entender, que el nuevo orden jurídico derivado de la Constitución y el fenómeno de la información.

A la entrada en vigor de la Constitución, para encontrar el fundamento de la responsabilidad civil por atentados al honor, ya no se hace necesario acudir al principio general de no causar daño a un tercero, que resulta de lo dispuesto en el artículo 1902 del Código Civil. Es en la propia Constitución donde en su artículo 18.1 se garantiza el honor como derecho fundamental de la persona humana, en cuyo respeto tiene su límite la libertad de expresión e información (Art. 20.4).

La doctrina jurídica española, en sus comentarios publicados en torno a la Constitución(14), ha clarificado suficientemente el carácter de norma jurídica de estos preceptos constitucionales, directamente aplicables por los Tribunales y configuradores de verdaderos derechos subjetivos, que todos-poderes públicos y particulares-están obligados a respetar (Art. 9 y 53). El quebrantamiento de este deber general de respeto, proclamado en la Constitución, confiere al agraviado un poder para impetrar la tutela jurisdiccional, que tanto puede ser de orden penal como civil. El ejercicio de este derecho por los particulares agraviados en su honor, es objeto de regulación en la Ley Orgánica $1 / 82$, de 5 de mayo, que contiene una normativa especifica de la responsabilidad civil derivada de los atentados contra la honra.

La consecuencia es que todo ese cuerpo de doctrina que sobre la materia se había elaborado con base en la teoría del acto ilícito extracontractual, sin otras normas particulares de referencia que no fueran las generales reguladoras de la culpa aquiliana, debe ser ahora constituda desde la perspectiva de ese principio general de garantía que la Constitución confiere a la honra como derecho fundamental, sin necesidad de acudir al artículo 1902 del Código Civil, y conforme a las reglas legales que sobre atribución de la responsabilidad civil se contiene en la citada Ley Orgá- 
nica, sin olvidar tampoco la "Declaración Universal de los Derechos Humanos", los "Pactos Internacionales de Derechos Civiles y Políticos" y la "Convención Europea de Salvaguardia de los Derechos del Hombre", en razón al valor interpretativo que les atribuye el artículo 10.2 de la Constitución; e incluso la manera misma en que esos textos han sido interpretados y aplicados por el Tribunal Europeo de los Derechos del Hombre de Estrasburgo.

En el texto de la Ley Orgánica 1/82, se configura el honor como un derecho de la personalidad, con los caracteres que la doctrina atribuye a tales derechos (irrenunciabilidad, inalienabilidad e imprescriptibilidad) (Artículo 1.3); pero su concepto no viene definido en términos de valores absolutos, sino "en función de datos variables según los tiempos y personas", como afirma la Exposición de Motivos. Su contenido queda delimitado por las leyes, los usos sociales ("las ideas que en cada momento prevalezcan en la Sociedad". son palabras empleadas en dicha Exposición de Motivos) y por el propio concepto que la persona tenga de su dignidad (art. 2.1.). Lo que tanto supone como afirmar que la concreción del concepto estará en función -en definitiva-de la opinión que los jueces tengan sobre la cuestión.

Ateniéndonos a lo dispuesto en los número 3 y 7 de su art. $7 .^{\circ}$, podríamos definir como atentado al honor a la divulgación de expresiones o hechos concernientes a una persona, sean o no relativas a su vida privada o de su familia, que por afectar a su reputación y buen nombre, la difama o hace desmerecer en la consideración general(15).

La responsabilidad civil derivada de este acto ilícito, no queda limitada por la Ley a la sóla resarcibilidad de los perjuicios ocasionados, sino. que también posibilita el ejercicio de una acción orientada a poner fin a ese ilícito comportamiento, y a rehabilitar la fama o crédito del ofendido (art. 9.2), en términos todos ellos muy similares a los que ya señaló la Sentencia antes comentada de 7 de febrero de 1962.

Para los supuestos de fallecimiento del titular del derecho, la Ley contiene una serie de reglas por las que se pretende compaginar la extinción de los derechos de la personalidad por la muerte de la persona, con la necesidad de tutelar la «memoria del difunto». De un lado, se atribuye la legitimidad para entablar la acción, o continuar la ya ejercitada por el ofendido, no por la cualidad de heredero del difunto, sino en atención a otros 
criterios no necesariamente coincidentes con esa condición (arts. 4, 5 y 6). Pero a su vez, como quiera que la indemnización tiene un contenido economico se hace preciso concretar a quién en definitiva se atribuye ese derecho patrimonial, que puede no serlo el legitimado para accionar (art. 9.4). Por lo demás, la regulación de "la memoria del difunto» o "los ultrajes a los muertos", parece inspirarse más en "sentimientos de piedad", que en la ofensa de "rebote" a los legitimados, es decir, que no es necesario que la ofensa al difunto se traduzca en una ofensa personal para los legitimados supervivientes(16).

En orden a la determinación del contenido del daño-en el que se comprenden tanto los "materiales o patrimoniales" como los «morales"-, establece la Ley una regla de presunción de su existencia que es en absoluto inoperante, porque si referida a los "daños materiales", en todo caso habrá que suministrar al Juez la prueba de la medida del daño; y si referida a los "daños morales", la propia naturaleza del derecho violado comporta por sí mismo su existencia, con lo que nada se añade, y en todo caso seguirá siendo necesario facilitar al Juez, los elementos precisos para su cuantificación.

Respecto a la medida del "daño moral", contiene la Ley una regla contraria al principio de la no proporcionalidad del daño con la culpa, propia de la función compensatoria que se le suele atribuir. Junto a esta función compensatoria del perjucio sufrido, también se le atribuye una ufunción satisfactorian para el perjudicado por lo hecho contra él, e incluso "punitiva", como ya había proclamado aquella sentencia de 1962 a que antes nos referimos. Lo curioso es que esta función a cumplir por la indemnización del daño moral, dado lo que al respecto se dispone en el artículo 9.3 de la Ley, se disocia por completo de la idea de culpa, y se conecta con la gravedad de la lesión (de la que es un dato clarificador a tener en cuenta la amplitud de su difusión)-función satisfactoria-, y con el beneficio obtenido, función punitiva donde la haya, que nos permite interrogarnos si no llegará a consagrarse la pena privada.

Son dos las grandes cuestiones marginadas de esta Ley: el derecho a la verdad y la interrelación entre el derecho a la honra y el derecho de información. 
La veracidad o certeza del hecho imputado, que jurídicamente puede configurarse como causa de justificación o excluyente de la antijuridicidad del acto, ha sido y es cuestión discutida, a la que las legislaciones han dado un trato distinto, acogiéndola en general, aunque en diferente grado 0 intensidad.

La omisión de su referencia en la Ley de protección civil del honor, nos lleva a preguntarnos si en ningún caso será admisible la alegación de la "verdad" en el proceso civil y, en su caso, cual sea la amplitud en que deba ser acogida. En la búsqueda de la respuesta adecuada a esta cuestión entran en juego los conceptos que sobre la honra y su esencia se mantengan, qué sea el derecho de información, y, muy particularmente, cual sea el carácter de la relación de este derecho con el derecho a la honra.

La "verdad" y los temas con ella conectados (el interés o relevancia pública del hecho verdadero revelado, el llamado derecho al olvido, la ausencia de malicia o la buena fe, como formula jurídica de equidad complementaria de la verdad), el tema de las inmunidades o privilegios de los informadores, son las cuestiones claves que nos darán la medida exacta de la relación entre ambos derechos. En verdad que, como ha escrito Carlos Soria, la «exceptio veritatis" no es sino el instrumento jurídico para asegurar la adecuación entre la honra y el derecho de información(17).

Una respuesta negativa a la pregunta que nos hemos formulado, fundada en la sola omisión de la Ley a esta cuestion, debe ser desechada por cuanto que nos conduciría a supeditar en exceso el derecho de información al derecho a la honra. La tutela que el Juez debe en nuestro orden constitucional tanto a uno como a otro, (no se olvide que el art. 20.1.d) consagra el derecho a una información "veraz"), obliga a encontrar fórmulas de adecuación, entre las que la "verdad" va a jugar un papel relevante.

El Juez civil, ante quien se formule una demanda de responsabilidad civil por una lesión del derecho al honor, vendrá también obligado a pronunciarse sobre estas cuestiones cuando en el proceso se aleguen por vía de excepción. Y la respuesta habrá de darla con sujeción a criterios propios del derecho privado, y no por aplicación análogica de las normas del Código Penal.

En la propia Ley Orgánica 1/82 encontramos referencias sobre las que pudiera elaborarse un cuerpo de doctrina propio. La configuración del 
"honor" "en términos que permiten al juzgador la prudente determinación de la esfera de protección", como se dice en la Exposición de Motivos, y así resulta de lo dispuesto en el art. 2.1; el que se declare en su art. 8.1 que no deben reputarse "intromisiones ilegitimas" aquellas en que "predomine un interés histórico, científico o cultural relevanten; el ámbito de protección que en la Ley se reserva a la vida privada, son desde luego todos ellos puntos de referencia que pueden sernos de utilidad a este propósito.

El carácter prevalente que la jurisdicción penal tiene en nuestro sistema jurídico, al que expresamente se acoge la Ley Orgánica 1/82 (art. 1.2), quizá reduzca la aplicación práctica de esta Ley por la jurisdicción civil. Sin embargo, su actuación en vía civil puede ser el más acabado y adecuado instrumento jurídicio de tutela de estos derechos, si no concebimos la acción de responsabilidad civil como limitada sólo a cumplir una función indemnizatoria, sino que le atribuimos un carácter reparador más amplio, también extensivo a la eliminación del acto ilícito y rehabilitador de la buena reputación o fama del agraviado, como así había proclamado ya la jurisprudencia de la Sala $1 .^{a}$ del Tribunal Supremo, y así lo hace la Ley Orgánica 1/82 (artículo 9.2).

Como ventaja cabe señalar un ámbito de protección mucho más amplio, porque los presupuestos en que se funda la responsabilidad civil se miden con parámetros de mayor flexibilidad que cuando de la exigencia de responsabilidad penal se trata; y porque la ausencia de alguno de aquellos elementos en que ésta se sustenta, no excluye la existencia de. responsabilidad civil.

Se hace además innecesario extender el ámbito de protección penal de la honra a los supuestos de comisión culposa, como lo es aquella que ha venido en llamarse "difamación por ligereza», cuya tipificación se ha señalado como aconsejable por algún sector doctrinal(18), olvidando que el "honor" es también un derecho de la personalidad, cuya eficaz tutela podía obtenerse ya desde antes mediante el ejercicio de la acción de responsabilidad civil. Acción también suficiente para amparar la honra frente a las "difamaciones genéricas", en donde la imputación precisa de hechos deshonrosos es sustituida por calificaciones, juicios de valor u opiniones 
despreciativas o degradantes más o menos fundadas.

De esta suerte se hace factible, sin merma de su adecuada protección, reconducir la protección penal del honor a tan sólo aquellos supuestos de particular gravedad, caracterizados principalmente por el conocimiento de la falsedad del hecho deshonroso alegado e imputado.

Pero sobre todo lo anterior, entiendo que la acción de responsabilidad civil contribuye a la desdramatización de los conflictos. Reconduce el problema a sus justos límites: no se trata de un pulso, de una tensión entre informador y Administración de Justicia; no se trata de ver-cuando no lo haya-un ataque a la libertad de expresión; de lo que se trata es de encontrar el punto de adecuación entre estos dos derechos de la persona humana.

Este es el punto de referencia al que se debe mirar. Promover el ejercicio de las libertades, y asegurar su protección o tutela eficaz, es tarea que a todos nos compete y a la que todos estamos obligados constitucionalmente.

\section{NOTAS:}

(1) Jaime Santos Briz: "La responsabilidad civil. Derecho sustantivo y Derecho procesal», editorial Montecorvo, Madrid 1981, pp. 164 y 166.

(2) "La ley protege a los indivíduos contra cualquier ofensa ilícita o amenaza de ofensa a su personalidad fisica o moraln.

(3) José Puig Brutau: «Fundamentos de Derecho. Civion, T. I., V. I. p. 67; Bosch, Casa Editorial, Barcelona 1979. Luis Diez Picazo y Antonio Gullon: «Sistema de Derecho Civil», V. I., p. 374, editorial Tecnos, Madrid 1979 (3. a edición). José Manuel Martín Bernal: «Los derechos de la personalidad en la Constitución españolan, Revista General de Legislación y Jurisprudencia, Enero 1979, T. LXXVIII (246 de la colección), p. 32. Ricardo de Angel Yagüe: «La protección de la personalidad en el Derecho Privadon, Revista de Derecho Notarial, Enero-Marzo 1974, Año XXI, n. ${ }^{\circ}$ LXXXIII, pp. 132 y 133.

(4) Luis Díez Picazo y Antonio Gullon: obra citada.

(5) La sentencia antes citada de 6 de Diciembre de 1882 declaraba que no siendo valorable el honor en los delitos cometidos contra él, no es posible fijar la cantidad en que consista el perjuicio, ni imponer al delincuente, como responsabilidad civil consiguiente a la criminal, la de pagar una indemnización al ofendido. 
(6) Francisco de Asís Garcia Serrano: «El daño moral extracontractual en la jurisprudencia civilı, Anuario Derecho Civil, año 1972, p. 800, citando a este respecto a Aramburo y Gayoso.

(7) Ricardo de Angél Yagüe: obra citada, p. 32.

(8) Francisco de Asís Garcla Serrano: obra citada; Agustín Fernández Albor: «El daño moral en los delitos contra el honor", Revista General de Legislación y Jurisprudencia, Mayo 1967, T. LIV (222 de la colección), p. 817 y sigulentes; Luis Diez Picazo: «Estudios sobre jurisprudencia civil», Ed. Tecnos 1979, Madrid, p. 112.

(9). Aramburo y Gayoso, citados en el indicado trabajo de Francisco de Asís Garcia Serrano.

(10) Sentencia de 14 de Diciembre de 1917, 7 de Noviembre de 1919, y 12 de Marzo de 1928.

(11) Además de los citados, la de 25 de Junio de 1945, 13 de Junio de 1950, 28 de Febrero de 1959, 7 de Febrero de 1962, 4 de Junio de 1962, 27 de Enero de 1973.

(12) Las de 31 de Marzo de 1930 y 4 de Junio de 1962. Sobre la primera Luis Diez Picazo: "Estudios sobre la jurisprudencia civil", pp. 113 y 117. José María de la Cuesta Rute y Andrés de la Oliva Santos: "Tratamiento jurídico en España de la comunicación publicitaria llícita», "La Ley» núms. 282 y 285, 1981.

(13) Luis Diez Picazo: “Estudios de jurisprudencia civil» (p. 117).

(14) Eduardo García de Enterría: "La Constitución como norma jurídica" en "La Constitución Española de 1978" (Estudio sistemático dirigido por los profesores Alberto Predieri y Eduardo García de Enterría), pp. 90 a 102, Ed. Civitas, Ș. A., Madrid 1980; Jorge de Esteban: «El Régimen Constitucional Español», p. 128 y ss., Labọ Universitaria, Barcelona 1980; José Manuel Martín Bernal: obra citada; Fernando Garrido Falla: "Comentarios a la Constitución», ed. Civitas, Madrid 1980, pp. 128 y ss. y 579 y ss.

(15) La ley habla de «intromisiones ilegitimas", expresión claramente referida a la vida privada, lo que revela que el propósito inicial de sus redactores reducía su ámbito de protección a este derecho y al de la propia imagen, hasta el punto que el $n .^{\circ} 7 \mathrm{del}$ art. $7 .^{\circ}$ no iba en la redacción del Proyecto remitido por el Gobierno, siendo introducido en las discusiones del Senado (Revista del Poder Judicial n. ${ }^{\circ}$ 3, Junio 1982, p. 127).

(16) De Cupis: "El daño. Teoría general de la responsabilidad civil», p. 661, ed. Bosch, Barcelona 1975).

(17) Sobre toda esta problemática, Carlos Soria: «Derecho a la información y derecho a la honra". A. T. E., 1981, Barcelona.

(18) En este sentido, la Sentencia de la Sala 2. ${ }^{a}$ del Tribunal Supremo, de 23 de Noviembre de 1981, que por lo demás, junto con la de 21 de Octubre de 1976, excluye la posibilidad de comisión culposa de los delitos contra el honor. 